Tropical Journal of Pharmaceutical Research October 2021; 20 (10): 2199-2204

ISSN: $1596-5996$ (print); 1596-9827 (electronic) (C) Pharmacotherapy Group, Faculty of Pharmacy, University of Benin, Benin City, 300001 Nigeria.

\title{
Comparative efficacy and safety of alendronate and teriparatide in bone loss reduction and prevention of vertebral fracture in osteoporotic Chinese patients
}

\author{
Yujun Qi ${ }^{1}$, Wenyuan Wang ${ }^{2}$, Wenlin Sun ${ }^{1}$, Qiuyin Pan ${ }^{2 *}$ \\ ${ }^{1}$ Department of Rehabilitation Medicine, ${ }^{2}$ Department of Acupuncture, The Affiliated Huai'an No. 1 People's Hospital of Nanjing \\ Medical University, Huaian, Jiangsu 223300, China
}

*For correspondence: Email: qiuyinpan12@hotmail.com; Tel/Fax:0086-0517-80872262

Sent for review: 29 March 2021

Revised accepted: 26 September 2021

\begin{abstract}
Purpose: To compare the effect of teriparatide and alendronate (bisphosphonate, BPP) among Chinese patients with osteoporosis $(\mathrm{OoP})$.

Method: Chinese subjects aged $>40$ years with a history of vertebral/non-vertebral osteoporotic fragility/fractures were enrolled, and administered either teriparatide (TPT $20 \mu \mathrm{g} /$ day) subcutaneously or alendronate (BPP)10 mg orally once daily for 12 months. Bone mineral density (BMD), measured using $x$-ray techniques, and bone formation biomarkers such as osteocalcin [OTC] and bone alkaline phosphatase, were assessed at baseline, and after 6 and 12 months of treatment. The proportion of patients with fractures as well as fracture rate were also recorded. The safety of the drugs was evaluated based treatment emergent adverse events.

Result: In Chinese men with OoP, substantially greater improvement in BMD was observed in TPT group, compared to BPP group. TPT demonstrated substantially greater improvement in OTC and, bone alkaline phosphatase than in BPP. Also, patients treated with TPT had significantly lower incidence of new fracture than BPP group during the study period, irrespective of gender distribution (relative risk reduction at 6 and 12 months was 45 and $47 \%$ respectively). The results showed that TPT was superior to BPP in increasing BMD and bone formation biomarkers and reducing new fractures in both male and female patients with osteoporosis.

Conclusion: Teriparatide is effective and safe in reducing bone loss and preventing vertebral fractures in Chinese patients with osteoporosis. Furthermore, the results show that there is no gender difference in the efficacy and safety of teriparatide in osteoporosis.
\end{abstract}

Keywords: Teriparatide, Alendronate, Bisphosphonates, Osteoporosis, Fracture, Bone mineral density, Bone formation biomarkers

This is an Open Access article that uses a funding model which does not charge readers or their institutions for access and distributed under the terms of the Creative Commons Attribution License (http://creativecommons.org/licenses/by/4.0) and the Budapest Open Access Initiative (http://www.budapestopenaccessinitiative.org/read), which permit unrestricted use, distribution, and reproduction in any medium, provided the original work is properly credited.

Tropical Journal of Pharmaceutical Research is indexed by Science Citation Index (SciSearch), Scopus, International Pharmaceutical Abstract, Chemical Abstracts, Embase, Index Copernicus, EBSCO, African Index Medicus, JournalSeek, Journal Citation Reports/Science Edition, Directory of Open Access Journals (DOAJ), African Journal Online, Bioline International, Open-J-Gate and Pharmacy Abstracts

\section{INTRODUCTION}

Bone fracture will affect $>50 \%$ of population in the next 5 years, especially for the patients within the age group of $\geq 65$ year [1]. Although osteoporosis prevalence rate is higher in postmenopausal women, there are reports that the incidence rate of osteoporosis is gradually increasing in men > 60 years [2]. Low bone mineral density (BMD) is one of key reason for 
bone fracture among older men and women [3].

Bisphosphonates are the class of drugs which bind bone minerals and block the activity of osteoclasts [4]. This results in decreased bone remodeling, thereby slowing down bone loss and significantly improving the material properties of bone [5].

Teriparatide is human recombinant parathyroid hormone and was found effective in preventing bone loss by stimulating bone modelling and remodeling, which increases the bone mass that helps in protecting against the fracture [6]. The results of several clinical reports showing that teriparatide $(20 / 40 \mu \mathrm{g})$ was effective in increasing the BMD in dose dependent manner and thereafter preventing fractures [7].

Currently, no comparative study is available on the effect of TPT versus Bisphosphonates in Chinese men patients with osteoporosis and compare it between men and women. This is the first study to compare effect of TPT and Bisphosphonates in Chinese men and women who were suffering from osteoporosis to understand if gender affect the efficacies. Also, this study compared the outcome of teriparatide versus Bisphosphonates on BMD and bone formation biomarker. Also, comparative data on incidence of fractures was assessed. This study was also designed to directly compare the effects of teriparatide between men and women.

\section{METHODS}

\section{Patients and study design}

Chinese subjects aged $>40$ years with history of vertebral/non-vertebral osteoporotic fragility/fractures were enrolled. The study was initiated after obtaining ethical approval from the institutional ethics committee (IEC) of Nanjing Medical University, vide, approval no. IEC/NMJ$20 / 783 / 05 / N-398$. The study was conducted in line with the ethical principles laid down in Helsinki Declaration and its later amendments [8].

Patients with any other bone disorder, hypoparathyroidism, hyperparathyroidism, or hyperthyroidism were excluded. The patients with American Society of Anesthesiologists (ASA) score of $\geq 4$, had history of bleeding disorder, uncontrolled diabetes, severe heart diseases, mental disorder, chronic renal disease, sleep disorder, pleural adhesions, or had undergone ipsilateral thoracic surgery were excluded. Also, patients with deformity in airways or spinal, or chest wall were also excluded.
Patients with suspected carcinoma or a history of carcinoma were excluded. The patients with any other pathology likely to affect the outcome of the study, and patients who received concomitant and contra-indicated medications, as well as patients undergoing any other form of surgery, were excluded.

\section{Treatments}

All eligible patients were randomized (1:1) to receive subcutaneous $20 \mu \mathrm{g} /$ day TPT or $10 \mathrm{mg}$ alendronate (BPP) orally once daily for approximately 12 months. Supplements such as vitamin $\mathrm{D}$ and calcium were administered to all patients who met eligibility criteria.

\section{Efficacy and safety assessments}

Bone mineral density was measured using X-ray techniques of the following timepoints: before and after 6 and 12 months of treatment. Biomarkers of bone formation such as osteocalcin [OTC] and alkaline phosphatase (bone) were assessed at following timepoints: before and after 6 and 12 months of treatment. Also, the proportion of patients with fractures rates were recorded. Safety of each patient was evaluated throughout study period.

Safety of both the study drugs was evaluated throughout study period of 12 months by recording treatment emergent adverse events in each treatment group. Also, data of men were compared with Postmenopausal women.

\section{Statistical methods}

Sample size calculation was not applicable for this study as the current study belongs to pilot study. However, we have included at least 200 evaluable patients in our study. The data which belongs to numerical variable or quantitative variable was analyzed using appropriate statistical method such as student $t$-test if data was parametric, otherwise Man Whitney test. Categorical variable or qualitative variable was analyzed using appropriate statistical method such as Chi-square and fisher exact based on the number of patients in each category.

Data related to variable with greater variation in response was analyzed using non-parametric test. Graph Pad prism was used to analyze the data. Mean (SD) was reported for all numerical variable such as BMD, whereas median was used to present data related to level of bone biomarkers.

Trop J Pharm Res, October 2021; 20(10): 2200 


\section{RESULTS}

\section{Patient characteristics}

A total of 230 patients were screened and of these, 200 patients were enrolled. Their data were analyzed using appropriate statistical tests. In both groups, patient data were comparable (Table 1).

Table 1: Patient characteristics

\begin{tabular}{|c|c|c|}
\hline Parameter & $\begin{array}{c}\text { TPT } \\
\mathbf{N}=100\end{array}$ & $\begin{array}{c}\text { BPP } \\
N=100\end{array}$ \\
\hline Age (yr) & $53.2(4.1)$ & $54.7(6.3)$ \\
\hline Sex, F/M (\%) & $50 / 50$ & $50 / 50$ \\
\hline Weight, kg & $68.2(4.2)$ & $69.2(5.2)$ \\
\hline BMI $\left(\mathrm{kg} / \mathrm{m}^{2}\right)$ & $26.2(1.8)$ & $27.4(3.5)$ \\
\hline $\begin{array}{l}\text { Duration of } \\
\text { treatment } \\
\text { (months) }\end{array}$ & $5.16(1.37)$ & $5.31(1.17)$ \\
\hline $\begin{array}{l}\text { Number }(\%) \text { of } \\
\text { patients with history } \\
\text { of at least } 1 \\
\text { vertebral fracture }\end{array}$ & $62(62 \%)$ & $56(56 \%)$ \\
\hline $\begin{array}{l}\text { Number (\%) of } \\
\text { patients with history } \\
\text { of at least } 1 \text { non- } \\
\text { vertebral fracture }\end{array}$ & $47(47 \%)$ & $49(49 \%)$ \\
\hline
\end{tabular}

\section{Bone mineral density}

In Chinese OoP patients, TPT demonstrate substantially greater improvement in BMD as compared to BPP (Figure 1). The LSM percentage change in BMD reported after TPT $20 \mu \mathrm{g} /$ day treatment in Chinese men was similar to the percentage change in Chinese women (Figure 1). This indicates that the superior efficacy of TPT in improving BMD irrespective of gender as compared to BPP after 6 months of treatment.

At 12 months, TPT demonstrated improvement in BMD as compared with BPP (Figure 2). Overall, effect of TPT on BMD was similar across all groups studied.

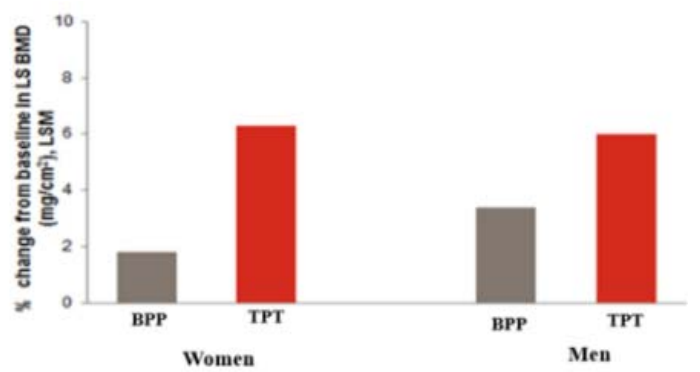

Figure 1: Change in BMD among Chinese patients (men and women) with osteoporosis after 6 months of treatment

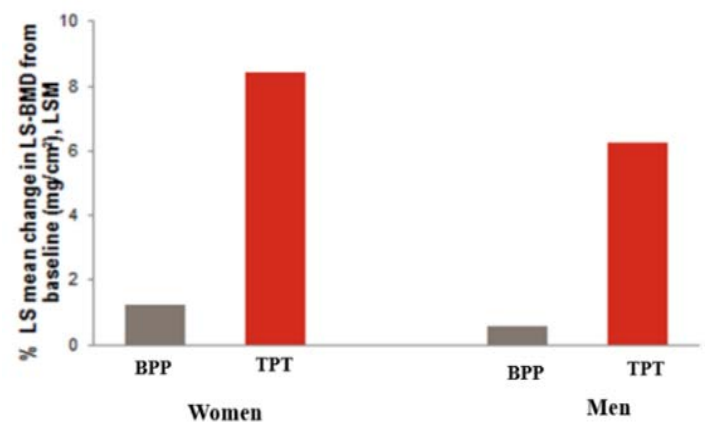

Figure 2: Change in BMD among Chinese patients (men and women) with osteoporosis after 6 months of treatment

\section{Biochemical markers}

In Chinese men and women with osteoporosis, a significant difference in percentage change in serum osteocalcin from baseline was noted with TPT $20 \mu \mathrm{g} /$ day compared to BPP after 6 months of treatment (median for men: teriparatide: 78.3 $\%$; BPP: $-16.3 \%$; $p<0.001$; median for women: teriparatide: $136.3 \%$; BPP: $-11.6 \%$; $p<0.001$ ) (Table 2).

The results showed that TPT was superior to BPP in improving bone formation biomarkers in Chinese patients of both the gender with osteoporosis.

Table 2: Change in serum osteocalcin $(\mathrm{ng} / \mathrm{ml})$ in Chinese men and women with osteoporosis after 6 months of treatment

\begin{tabular}{|c|c|c|c|c|c|c|}
\hline \multirow{2}{*}{$\begin{array}{l}\text { Time- } \\
\text { point }\end{array}$} & \multicolumn{3}{|c|}{ Women } & \multicolumn{3}{|c|}{ Men } \\
\hline & $\begin{array}{c}P P T \\
(N=50)\end{array}$ & $\begin{array}{c}B P P \\
(N=50)\end{array}$ & $\begin{array}{l}\text { Effect size } \\
\text { (TPT -BPP) }\end{array}$ & $\begin{array}{c}T P T \\
(N=50)\end{array}$ & $\begin{array}{c}B P P \\
(N=50)\end{array}$ & $\begin{array}{l}\text { Effect size } \\
\text { (TPT -BPP) }\end{array}$ \\
\hline Baseline* & 20.32 & 21.2 & - & 16.9 & 16.49 & - \\
\hline $\begin{array}{l}6 \text { Month* } \\
\text { Change (\%) } \\
P \text {-value }\end{array}$ & $\begin{array}{c}54.05 \\
136.3 \\
P<0.01\end{array}$ & $\begin{array}{c}17.3 \\
-11.6 \\
P<0.01\end{array}$ & $P<0.01$ & $\begin{array}{c}26.5 \\
78.3 \\
P<0.01\end{array}$ & $\begin{array}{c}12.81 \\
-16.3 \\
P>0.05\end{array}$ & $P<0.001$ \\
\hline
\end{tabular}

${ }^{*}$ Presented as median. TPT: Teriparatide; BPP: Bisphosphonates 
Table 3: Change in alkaline phosphatase (bone, $\mu \mathrm{g} / \mathrm{L}$ ) in Chinese men and women with osteoporosis after 6 months of treatment

\begin{tabular}{|c|c|c|c|c|c|c|}
\hline \multirow{2}{*}{$\begin{array}{l}\text { Time- } \\
\text { point }\end{array}$} & \multicolumn{3}{|c|}{ Women } & \multicolumn{3}{|c|}{ Men } \\
\hline & $\begin{array}{c}\text { TPT } \\
(\mathrm{N}=50)\end{array}$ & $\begin{array}{c}\text { BPP } \\
(N=50)\end{array}$ & $\begin{array}{l}\text { Effect size } \\
\text { (TPT -BPP) }\end{array}$ & $\begin{array}{c}\text { TPT } \\
(\mathrm{N}=50)\end{array}$ & $\begin{array}{c}\text { BPP } \\
(N=50)\end{array}$ & $\begin{array}{l}\text { Effect size } \\
\text { (TPT -BPP) }\end{array}$ \\
\hline \multicolumn{7}{|l|}{ At 6 months } \\
\hline Baseline* & 10.80 & 9.80 & - & 10.50 & 10.92 & - \\
\hline 6 month* & 17.35 & 12.34 & - & 16.45 & 11.22 & - \\
\hline $\begin{array}{l}\% \text { Change } \\
P \text { value }\end{array}$ & $\begin{array}{c}37.35 \\
p<0.001\end{array}$ & $\begin{array}{c}14.55 \\
p<0.001\end{array}$ & $p<0.001$ & $\begin{array}{c}29.43 \\
p<0.001\end{array}$ & $\begin{array}{c}9.35 \\
p<0.005\end{array}$ & $P<0.001$ \\
\hline \multicolumn{7}{|l|}{ At 12 months } \\
\hline Baseline* & 9.91 & 9.87 & - & 10.32 & 10.10 & - \\
\hline 6 month* & 18.5 & 11.37 & - & 16.40 & 12.40 & - \\
\hline $\begin{array}{l}\text { Change (\%) } \\
P \text {-value }\end{array}$ & $\begin{array}{l}51.97 \\
<0.001\end{array}$ & $\begin{array}{l}18.87 \\
<0.01\end{array}$ & $<0.001$ & $\begin{array}{c}28.79 \\
<0.001\end{array}$ & $\begin{array}{c}11.33 \\
<0.001\end{array}$ & $<0.001$ \\
\hline
\end{tabular}

A substantial improvement in \% change for bone formation markers was observed with teriparatide $20 \mu \mathrm{g} / \mathrm{day}$ as compared to BPP after 6 months of treatment (Table 3 ). Both the are effective in increasing the serum bone-specific alkaline phosphatase levels from baseline, however, between group comparison demonstrates that teriparatide significantly has greater improvement in levels of bone biomarker. At 12 months, a similar trend of significant difference in percentage change in serum bone-specific alkaline phosphatase from baseline was noted with TPT $20 \mu \mathrm{g} /$ day than BPP (Table 3). Overall, the effect of TPT 20 on osteocalcin and bonespecific alkaline phosphatase was similar across both the genders.

A summary of incidence of fracture among Chinese men and women is presented in Table 4. The patients treated with TPT had significantly lower incidences of new fracture as compared to BPP group during study period irrespective of gender distribution. The relative risk reduction of 0.55 for vertebral fractures for both the groups, this indicates that $45 \%$ of patients in TPT has lower chances of experiencing new fracture as compared to the patients treated with BPP. Similar trend of results was observed for nonvertebral fractures for both the treatment group. For non-vertebral fractures, the relative risk of 0.53 for both the groups, this indicates that $47 \%$ of patients in TPT had lower chances of experiencing new fracture as compared to the patients treated with BPP.

During study period, none of patients treated either TPT or BPP experienced serious adverse event, with approx. $33 \%$ of patients in both the groups experienced TEAEs. The most common adverse events observed in both the treatment group was dizziness ( $9 \%$ ), followed by ALT and
AST increase. The number of patients with AEs was found comparable in both the group. Overall, both treatments were found safe.

Table 4: Summary of incidence of fracture after 12 months of treatment with TPT and BPP among Chinese men and women

\begin{tabular}{|c|c|c|}
\hline Variable & $\begin{array}{l}\text { Teriparatide } \\
(\mathrm{N}=100)\end{array}$ & $\begin{array}{c}\text { Bisphosphonates } \\
\text { [BPP] } \\
(\mathrm{N}=100)\end{array}$ \\
\hline \multicolumn{3}{|c|}{ Vertebral fractures } \\
\hline Relative risk & & 0.55 \\
\hline $\begin{array}{l}\text { Relative risk } \\
\text { reduction } \\
(\%)\end{array}$ & & $45 \%$ \\
\hline$P$-value & & $<0.001$ \\
\hline \multicolumn{3}{|c|}{ Non-vertebral fractures } \\
\hline Relative risk & & 0.53 \\
\hline $\begin{array}{l}\text { Relative risk } \\
\text { reduction } \\
(\%)\end{array}$ & & $47 \%$ \\
\hline$P$-value & & $<0.001$ \\
\hline
\end{tabular}

\section{DISCUSSION}

This was the first study to compare the effect of teriparatide versus Bisphosphonates in men and women to understand if gender affect the efficacy. Also, effect of teriparatide versus Bisphosphonates on BMD and bone formation biomarker including prevention of occurrence of new fractures was assessed.

In the present study, compared to BPP, teriparatide demonstrated substantially greater improvement in BMD among Chinese men. The effect of teriparatide in Chinese men was comparable to the percentage change in Chinese women. This indicates that the superior efficacy of TPT $20 \mu \mathrm{g} /$ day in improving BMD is irrespective of gender as compared to BPP after 6 and 12 months of treatment. This finding is

Trop J Pharm Res, October 2021; 20(10): 2202 
consistent with other studies in which men with IO randomized to receive teriparatide displayed a noteworthy improvement in BMD as compared with those on placebo. Orwoll et al. reported that the BMD (LS region) increased by $6 \%$ for a median duration of 11 months [11]. Langdahl et al reported that men treated for 18 months experienced a $7.0 \%$ lumbar spine BMD increase [24].

In the GHDG study, a numerically larger percentage increase in BMD (LS region) was observed after teriparatide treatment $(6.01 \%)$. In addition, percentage change in BMD was found similar in Chinese men and women who received teriparatide 20- $\mu \mathrm{g} /$ day for 12 months. This indicates that the benefits of TPT was comparable Chinese men and women. Moreover, a similar trend of effect of TPT was observed in White women and men after long term treatment, which indicates that there are no ethnic differences in the effect of teriparatide on BMD (LS region) [9]. A 12-month treatment with TPT in this study offer similar kind of efficacy results as noted with alendronate therapy $(7.1 \%)$ in White men with osteoporosis after 2 years of treatment [10]. This indicates that teriparatide therapy, has a faster onset of action than alendronate, is effective in men with osteoporosis. The rapid onset of action is possibly due to its stimulation of osteoblastic activity [11], which increases bone mass [12,13].

In Chinese patients, regardless of sex, teriparatide treatment increased median serum levels of osteocalcin as teriparatide preferentially stimulates osteoblasts. The effect of teriparatide on osteocalcin was consistent with previous findings [14]. Also, in the present study, regardless of sex, we observed noteworthy improvement in serum bone-specific alkaline phosphatase after treatment with teriparatide, after a 6-month or 12-month follow-up period; possibly due to the effect of teriparatide on osteoblast which is mainly involved in bone formation. Overall, the effect of TPT $20 \mu \mathrm{g} / \mathrm{day}$ on osteocalcin and bone-specific alkaline phosphatase was similar between Chinese men and women and consistent with the Caucasian patients with osteoporosis, which indicates that there are no ethnic differences in the effect of teriparatide on osteocalcin or bone-specific alkaline phosphatase.

The most common adverse event was dizziness among Chinese men and women. Taken together, the safety results observed in this study are very similar to and consistent with previously published data [8] Overall, safety profile of teriparatide $20 \mu \mathrm{g} /$ day was also found to be similar in Chinese men and women.

\section{Limitations of the study}

This study was conducted at a single study center in China. Thus, the results of the present trial cannot to be generalized to the Chinese population. Therefore, a randomized, parallel group clinical trial with appropriate sample size is required to confirm the findings of this study.

\section{CONCLUSION}

The results show that TPT is superior to BPP in increasing BMD and bone formation biomarkers as well as in lowering new fractures in Chinese men and women with osteoporosis. Moreover, there are no gender differences in efficacy and safety with regard to the clinical use of teriparatide in osteoporosis.

\section{DECLARATIONS}

\section{Conflict of Interest}

No conflict of interest associated with this work.

\section{Contribution of Authors}

The authors declare that this work was done by the authors named in this article and all liabilities pertaining to claims relating to the content of this article will be borne by them.

\section{Open Access}

This is an Open Access article that uses a funding model which does not charge readers or their institutions for access and distributed under the terms of the Creative Commons Attribution License (http://creativecommons.org/licenses/by/ 4.0) and the Budapest Open Access Initiative (http://www.budapestopenaccessinitiative.org/rea d), which permit unrestricted use, distribution, and reproduction in any medium, provided the original work is properly credited.

\section{REFERENCES}

1. Siddiqui NA, Shetty KR, Duthie EH Jr. Osteoporosis in older men: discovering when and how to treat it. Geriatrics 1999; 54:27-28

2. Wang Y, Tao Y, Hyman ME, Li J, Chen Osteoporosis in China. Osteoporos Int 20 2009;20(10):1651-1662

3. Uusi-Rasi K, Karinkanta S, Tokola $K$, Kannus $P$, and Sievänen H. Bone Mass and Strength and Fall-Related 
Fractures in Older Age. J Osteoporos 2019; 2019:5134690.

4. Hodsman AB, Bauer DC, Dempster DW, Dian L, Hanley $D A$, Harris ST, Kendler $D L$, McClung MR, Miller $P D$, Olszynski WP, et al. Parathyroid hormone and teriparatide for the treatment of osteoporosis: a review of the evidence and suggested guidelines for its use. Endocr Rev 2005; 26:688-703

5. Neer RM, Arnaud $C D$, Zanchetta JR, Prince $R$, Gaich $G A$, Reginster JY, Hodsman $A B$, Eriksen EF, IshShalom S, Genant HK, et al. Effect of parathyroid hormone (1-34) on fractures and bone mineral density in postmenopausal women with osteoporosis. N Engl J Med 2001; 344:1434-1441

6. Langdahl BL, Marin F, Shane E, Dobnig H, Zanchetta JR, Maricic M, Krohn K, See K, Warner MR. Teriparatide versus alendronate for treating glucocorticoid-induced osteoporosis: an analysis by gender and menopausal status. Osteoporos Int 2009; 20(12):2095-2104

7. Orwoll $E$, Ettinger $M$, Weiss $S$, Miller $P$, Kendler $D$, Graham J, Adami S, Weber K, Lorenc R, Pietschmann $P$, et al. Alendronate for the treatment of osteoporosis in men. N Engl J Med 2000; 343:604-610

8. World Medical Association Declaration of Helsinki. Recommendations guiding physicians in biomedical research involving human subjects. JAMA 1997; 277:925-926.
9. Bodenner D, Redman C, and Riggs A. Teriparatide in the management of osteoporosis. Clin Interv Aging 2007; 2(4): 499-507.

10. Orwoll $E$, Ettinger $M$, Weiss $S$, Miller $P$, Kendler $D$, Graham J, Adami S, Weber K, Lorenc R, Pietschmann $P$, et al. Alendronate for the treatment of osteoporosis in men. N Engl J Med 2000; 343:604-610

11. Rosen CJ, Bilezikian JP. Clinical review 123: Anabolic therapy for osteoporosis. J Clin Endocrinol Metab 2001; 86:957-964

12. Bellido T, Ali AA, Plotkin $L I, F u$ Q, Gubrij I, Roberson $P K$, Weinstein RS, O'Brien CA, Manolagas SC, Jilka RL. Proteasomal degradation of Runx2 shortens parathyroid hormone induced anti-apoptotic signaling in osteoblasts. A putative explanation for why intermittent administration is needed for bone anabolism. J Biol Chem 2003; 278(50):50259-50272

13. Miyauchi A, Matsumoto $T$, Shigeta $H$, Tsujimoto $M$, Thiebaud $D$, Nakamura T. Effect of teriparatide on bone mineral density and biochemical markers in Japanese women with postmenopausal osteoporosis: a 6-month dose-response study. J Bone Miner Metab 2008; 26(6):624-634

14. Kurland ES, Cosman F, McMahon DJ, Rosen CJ, Lindsay $R$, Bilezikian JP. Parathyroid hormone as a therapy for idiopathic osteoporosis in men: effects on bone mineral density and bone markers. J Clin Endocrinol Metab 2000; 85:3069-3076. 